\title{
Current Trends and New Challenges for Canada’s Resettlement Program
}

\author{
Michael Casasola
}

\begin{abstract}
References to resettlement in the C-31 legislative package reflected changes that were already underway as part of the Refugee Resettlement Model (RRM). While these changes result in visible improvements to Canada's refugee resettlement program, new challenges are surfacing, as Canada's program attempts to be responsive to global resettlement needs.

This article follows the development of Canadian and international contemporary resettlement policy and identifies trends for the future. It argues that Canada must continue to make policy and procedural changes to its resettlement program so that it can respond to current and future resettlement challenges.
\end{abstract}

\section{Résumé}

Les références faites à la réinstallation dans le paquet de mesures législatives du projet de loi C-31, reflétaient en fait des changements déjà en voie d'exécution en tant qu'éléments du Modèle de Réinstallation de Réfugiés (MRR). Alors que ces changements apportent des améliorations bien visibles au programme du Canada pour la réinstallation des réfugiés, d'autres défis ont surgi pour confronter les efforts de ce même programme de répondre aux besoins en matière de réinstallation sur le plan global.

Cet article suit le développement de la politique contemporaine internationale et celle du Canada en matière de réinstallation, et essaye d'identifier les tendances pour l'avenir. Il soutient que le Canada doit continuer à apporter des changements à son programme de réinstallation tant au niveau de la politique d'ensemble que dans les procédures suivies, affin de pouvoir répondre aux défis courants et les défis à venir dans le domaine de la réinstallation.

\section{Introduction}

C-31, the Canadian government's most recent legislative package, devoted little attention to the overseas selection of refugees for resettlement. The proposals were predictable, a continuation of the direction Citizenship and Immigration Canada (CIC) has set out for Canadian resettlement. Over the last few years, Canada's resettlement program has been slowly shifting from one described, at its worst, as an immigration program with a humanitarian label, to a program that emphasizes protection in the selection of refugees for resettlement. While many of the changes being made are welcome, Canada's resettlement program has difficulty keeping pace with international resettlement needs. If Canada is to be responsive to existing and future needs, it will have to continue to adapt and change its resettlement policies and procedures.

Refugee realities and global resettlement needs have changed significantly since the introduction of the $1976 \mathrm{Im}$ migration Act. Thousands of refugees from a variety of ethnic groups have been resettled in response to a number of refugee crises. The experience of resettling these refugees and changing realities forced all players to reassess their policies and programs. In the mid-9os, following an internal evaluation of the United Nations High Commissioner for Refugee's (UNHCR) resettlement program, the UNHCR revamped its resettlement efforts. It updated the UNHCR Resettlement Handbook, started a resettlement staff-training drive, made a more concerted effort at international cooperation, actively promoted UNHCR's resettlement policy among existing resettlement countries, and sought out new countries with which to become involved in resettlement.

Not long after the UNHCR started overhauling its resettlement program, Canada also began to work on improving its resettlement program. Yet while it makes alterations to its existing programs, new challenges emerge. Certain 
barriers have been reduced: greater emphasis is now placed on resettling de facto families, reuniting refugee families, and evaluating refugees' protection needs rather than their ability to settle quickly in Canada. Unfortunately, Canadian security and medical requirements are beginning to replace these problems as the obsessions and obstacles for the future. These new barriers will also need to be addressed. Thus, if Canada's program is going to assist the people it intends to help, it must continue to adjust its policy and procedures through a series of new measures beyond those outlined in C-31.

\section{Resettlement as a Tool of Protection and a Durable Solution}

Resettlement is offered for a number of reasons:

- Sharing the international burden and responsibility, as a way to partially relieve countries already providing asylum to many refugees

- Protecting refugees from repatriation when they are threatened with removal to the country of persecution

- Protecting refugees who are detained, in danger, or vulnerable in their country of asylum

- Providing a durable solution for refugees who face no likely possibility of returning home or of being able to integrate into their country of asylum

- Providing medical treatment to refugees because they require medical treatment that is unavailable in the country of asylum. ${ }^{1}$

From the late 1970s onward, the Indochinese resettlement movement in many ways defined the international resettlement experience. As a result, two schools of thought developed. The ability of the Indochinese to integrate and achieve independence in new countries demonstrated to many the value of resettlement as a durable solution. At the same time, the Indochinese movement led to concerns in some quarters about a "pull-factor" - that the availability of resettlement was allegedly encouraging people to flee. As a result, some suggested that resettlement should be left to only those in need of protection.

Emphasizing resettlement as a durable solution recognizes the ability of resettlement to provide a solution for the many refugees unable to benefit from the other two durable solutions-to voluntarily repatriate and receive protection in their country of origin or receive effective and ongoing protection in their country of asylum through local integration.

While all refugees have protection concerns, and many refugees are vulnerable, promoting resettlement solely as a tool for protection limits its use for refugees who face imminent legal or physical protection threats in their country of asylum, such as involuntary repatriation, detention, or physical harm. While the UNHCR is certainly not aware of all refugees who face such impending danger, the reality is that the number of refugees facing urgent or emergency protection concerns is actually quite small. In 1999 there were 114 urgent and emergency submissions by the UNHCR to resettlement countries. For the first five months of 2000, the UNHCR submitted seventy-six cases. As a result, a resettlement program, which emphasizes protection solely, is ultimately a very small program.

The UNHCR has resolved this debate by recognizing that resettlement is simultaneously a tool of protection and a durable solution. In determining refugees' need for resettlement, their need for protection must be considered, along with their need for a durable solution, and any special considerations that relate to the individuals or to their families. Whenever circumstances permit, the UNHCR promotes and facilitates the voluntary return of refugees to their countries of origin. Nevertheless, there is no hierarchy among durable solutions.

Realistically, the number of refugees in need of a durable solution vastly exceeds the number of resettlement places available globally. In determining who among those refugees in need of a durable solution are resettled, the UNHCR has encouraged countries to base resettlement selection decisions on the "hierarchy of needs" approach taken in the UNHCR's Resettlement Handbook. Among the many refugees who are neither able to return to their home countries nor to settle locally in their initial countries of asylum, the Resettlement Handbook tries to identify those with the most acute need for resettlement. These are:

First, refugees with legal and physical protection needs

Then, refugees with special needs, which include:

- medical needs

- survivors of violence and torture

- women at risk

- family reunification

- children and adolescents

- elderly refugees

Last, other refugees without a durable solution ${ }^{2}$

Within these categories, the highest resettlement priority is given to refugees with legal and physical protection needs. As the Resettlement Handbook notes, “. . . in cases not related to immediate protection concerns, particularly those falling under the criteria of lack of local integration prospects, a decision to refer for resettlement may be influenced by the availability of spaces." 
Determining whether a refugee needs resettlement, or whether another durable solution is available, must be done individually. Even when a given solution may be available for other members of a group to which the applicant belongs, the durable solution may not be available for the individual applicant.

\section{Canadian Legislative Development}

Canada's resettlement program has offered protection and a durable solution to thousands of refugees. Its current approach originated with the 1976 Immigration Act. Over the years, this approach has scarcely changed. Basically, the act and regulations set out that all resettled refugees must be found to be eligible, meaning they must be either a convention refugee seeking resettlement or a member of a Humanitarian Designated Class, have no possibility of a durable solution, demonstrate an ability to become independent upon arrival in Canada, and meet Canada's immigration admissibility criteria (criminal, security, and medical restrictions - not pose a danger to public health or have a disability that will pose an excessive medical demand or cost for Canada.) Eligibility and admissibility is determined by Canadian visa officers at Canadian missions throughout the world.

This approach worked well in the era of the resettlement of Indochinese refugees, during which refugees were primarily based in accessible refugee camps. Refugees waited in a sort of resettlement queue until resettlement spaces became available in resettlement countries. Since that time, many new refugee movements and challenges have developed, spanning the entire globe. Canada has attempted to respond to many of these movements, with varying degrees of success.

While hundreds of thousands of refugees have been resettled under Canada's resettlement program, serious weaknesses have been evident. Canada's lengthy and slow processing has generally meant that its resettlement program has been unable to respond to those refugees with urgent protection needs. In its efforts to ensure that refugees integrated in Canada, it effectively barred those who were seen as likely to have difficulty integrating through "ability to successfully establish" criteria, or who might present "excessive" medical demands. Canada's efforts to separate family reunification concerns from refugee protection concerns resulted in situations where members of separated refugee families found themselves ineligible for either program. Finally, Canadian visa posts, which are responsible for refugee admission, were often located in ar- eas far removed from refugee populations. It was recognized that Canada's resettlement program was not responding to these challenges.

\section{Refugee Resettlement Model (RRM)}

The development of the Refugee Resettlement Model (RRM) began in September 1997. At that time Citizenship and Immigration Canada faced great difficulty in meeting its resettlement quota. This crisis helped CIC recognize the need to re-examine its resettlement processing. Through a series of consultations, workshops, and working groups involving operational partners, an operational model was developed known as the RRM.

The RRM attempts to address the problems within Canada's resettlement program by making adjustments to the refugee resettlement system. The RRM emphasizes concrete practical proposals within budgetary constraints. The adjustments include legislative, policy, and operational proposals. Instead of approaching the tasks of resettlement in isolation, the RRM looks at refugee resettlement as an integrated continuum through the six components of identification, locating, selection, destining, orienting, and finally settling in Canada.

Within the RRM's numerous recommendations are a number of overall themes. As previously noted, resettlement is to be viewed as a continuum. In order for it to take place, effective communication and feedback need to be established among all the partners involved in the processing stages. Improved training has been identified as a need by government and NGos. Partnerships are to be strengthened, through existing and new operational partnerships.

Parallel to the development of the RRM, the legislative review was taking place. The report of the Legislative Review Advisory Group, Not Just Numbers, proposed a new legislative and policy foundation for refugee selection, including refugee resettlement. Unlike the RRM, it focused on policy and avoided operational issues. The Legislative Review Advisory Group emphasized protection of those most needy and most vulnerable at first opportunity. While there was little likelihood that some of its more dramatic recommendations would be put into place, the report's significance was that it acknowledged the existence of barriers that had long been identified by NGos in Canada.

The federal government's responses to Not Just Numbers was Building a Strong Foundation for the $21^{\text {st }}$ Century: New Directions for Immigration and Refugee Policy and Legislation. It also recognized the barriers identified by the Legislative Review Advisory Group and in response pro- 
posed a "more responsive overseas resettlement program.", It proposed four policy measures that were adopted by the RRM:

- Shift the balance toward protection rather than the ability to settle successfully in selecting refugees

- Make a more concerted effort to facilitate the unity and reunion of refugee families

- Develop a closer relationship with non-governmental partners

- Ensure the immediate entry of urgent protection cases.

\section{c-31}

C-31, the legislative follow-up to Building a Strong Foundation, included little about resettlement. Instead, the C-31 legislative package relegated to regulations most areas of Canadian immigration law that related to resettlement. These regulatory proposals mirrored proposals in the RRM and Building a Strong Foundation.

Overall, the initiatives on resettlement promised in the C-31 legislative package were positive. It would provide a stronger legal foundation for the policy changes proposed under the RRM and Building a Strong Foundation by putting them into regulations. It also included a commitment to remove the excessive medical demand provision for resettled refugees, thus eliminating this barrier for refugees with physical disabilities in need of resettlement. However, there were negative provisions included as well. The Federal Court "leave" requirement would have limited a refugee applicant's appeal rights, and the introduction of admission ceilings could be applied to resettled refugees.

Unfortunately the most negative aspect of the legislative package was that the many positive resettlement initiatives were presented as a counter to some of the more punitive actions the government planned in order to limit access to the refugee determination system in Canada. In fact, the resettlement initiatives became an important part of the selling of the bill to the Canadian public. The urgent protection pilot and the policy commitment to ensure the immediate entry of urgent protection cases were presented in response to questions about limitations that c-31 would present for refugees seeking asylum in Canada. Resettled refugees were presented as part of the refugees using the "front door." And by providing such refugees greater access, Canada suggested it had the moral authority to limit access to those refugees described as using the "back door."

This approach pitted the needs of two refugee groups against each other. Pitting refugee populations against each other is not new. Resettlement has often been threatened by arguments about the cost of asylum-seekers. The argu- ment usually begins with the recognition that resources are finite. If the number of asylum seekers increases, then costs increase. Thus the money available for refugee resettlement decreases, and fewer refugees are resettled. Of course, if these arguments were indeed genuine, then refugee resettlement would increase when the number of asylum seekers diminished. However, this never happens. In the case of the humanitarian evacuation of Kosovars in 1999, some Nordic countries reduced their resettlement numbers to accommodate this new emergency, in effect denying a durable solution to one group while increasing temporary protection for another.

\section{International Context}

Historically there have been two groups among resettlement countries. ${ }^{5}$ One is the group of countries with immigration programs who process applications at their embassies throughout the world. As countries of immigration, they introduce immigration-related criteria and restrictions. They tend to take relatively large numbers, process slowly, and be stereotyped as "taking the cream of the crop" among the refugee population. In contrast, those in the other group are smaller European countries, mostly Nordic, which take relatively smaller numbers, process them quickly through their headquarters, take only referrals from the UNHCR with few restrictions, and are believed to be taking the most difficult cases.

This simplification of resettlement countries' programs has become dated. It is true that most of the world's resettled refugees end up in countries of traditional immigration. Of the approximate 100,000 refugees resettled throughout the world, over three-quarters will end up in the United States. While the Nordic countries are still willing to receive refugees refused by other countries or refugees who cannot await lengthy processing, the stereotype that countries with immigration programs take refugees who are the "cream of the crop" is somewhat outdated. The U.S. has made serious changes to its resettlement program over the last few years. It places priority upon refugees identified by the UNHCR or American embassies. In selecting the 76,000 to 80,000 refugees to be resettled next year, the United States will not consider a refugee's integration potential.

The number of resettlement countries has also changed. New countries have become involved in resettlement. The new countries include Argentina, Benin, Brazil, Burkina Faso, Chile, Iceland, Ireland, and Spain. Most recently the United Kingdom has also expressed its intention of becoming an official resettlement country. While these countries 
have introduced relatively small programs, collectively they expand the range of possible resettlement destinations.

Among the new resettlement countries, Benin and Burkina Faso have provoked significant discussion. The involvement of these two developing countries underlines the notion that resettlement should not be understood as a euphemism for resettlement to the U.S.A. and an expected improved quality of life, but that resettlement genuinely comprises finding an alternative durable solution to a refugee's current circumstance. Benin and Burkina Faso's involvement has been by no means token. Indeed, they have played an important role in responding to resettlement needs. While the two countries have taken only a small number of refugees each, the refugees being resettled include refugees with serious protection concerns who were not accepted by other countries. For example, traditional resettlement countries prohibit polygamy, making the resettlement of polygamous families difficult. However, the fact that Benin does not prohibit such practice has made it possible for it to respond to this resettlement need. In this way, new resettlement countries expand the range of resettlement possibilities.

Nevertheless, the involvement of many of the Nordic countries remains important because of their responsiveness to UNHCR criteria and their ability to resettle cases quickly. These countries also remain willing to take refugees who may have serious settlement difficulty. For example, of the approximately 500 "quota refugees" or resettled refugees Denmark will select, 20 or more will be "medical cases"- cases selected because of their need for medical treatment, which countries with medical restrictions, such as Canada, would not admit.

While in recent times the aggregate number of refugees being resettled has not increased, refugee resettlement is being offered to refugees in more countries. Until now, there has been substantial resettlement out of Europe. From the beginning of 1997 through the end of 1999, more than 40,00o Bosnian refugees were resettled to Australia, Canada, and the United States. ${ }^{6}$ Though this resettlement movement has been declining, a substantial increase has been taking place in the Middle East, South Asia, and Africa. The United States has been selecting refugees in significantly larger numbers in Africa. In fiscal year 2001 the United States will select 20,00o refugees from Africa. In fiscal year 1998 it was resettling only 7,000 . $^{7}$ This amounts to an almost 300 per cent increase in three years. Despite this increase, some in the United States view this as inadequately responsive to the need. ${ }^{8}$

The pattern of resettlement activities in Africa has also changed over the last few years. As recently as 1997, more than three-quarters of the refugees resettled from Africa were Somalis in Kenya. In 1999 Somalis still remained the largest group of African refugees with identified resettlement needs, but resettlement benefited thirty other African nationalities as well that year. ${ }^{9}$

\section{How Has Canada Changed?}

While the number of refugees resettled has remained at about 10,000 each year, whom Canada selects has changed. Canada has dramatically increased the number of "special needs" refugees resettled to Canada, from 89 people in 1996 to over 550 in 2000, not including the large number of resettled Kosovars. These "special needs" refugees are individuals who have particular difficulty resettling, including women at risk, the elderly, and those with medical needs.

While Canadian regulations have not changed, in practice visa posts have already begun following the policy directions set out in Building a Strong Foundation, by diminishing the application of "ability to establish" criteria. It seems quite likely that with future legislation Canada will remove the application of this requirement from refugees with urgent protection concerns or from "vulnerable persons." ${ }^{10}$

Canada is also changing where it selects refugees for resettlement. While Canada selected a disproportionate number of refugees from Europe in the 1990s, ${ }^{11}$ one of Canada's unsung successes has been the shift it has been making each successive year in selecting increasing numbers of refugees from Africa and the Middle East, to be more in keeping with the areas of the world where refugees are located. Though the numbers have not yet been finalized at the time of writing, it is expected that in 2001, Africa will finally overtake Europe as the largest source of refugees to be resettled to Canada. While the targets for most of the posts in Africa will increase slightly, the numbers to be selected out of West Africa are expected to double from 225 persons to 450 persons.

Canada has also begun taking some urgent cases more quickly. In 2000, it established the Urgent Protection Pilot (UPP) running in three sites: Ankara, Nairobi, and Islamabad. The UPP will result in the resettlement of over thirty people with urgent protection needs, most en route to Canada in a three-to-five-day time frame set out in the Upp. ${ }^{12}$ The Canadian initiative has apparently inspired the United States to attempt to develop its own urgent protection program.

All these changes have been significant accomplishments for Canada, given that many of them were completed at a time when Canada and its partners were experiencing significant fiscal restraint. While the direction in which Canada 
has been moving is encouraging, it is likely to face greater operational challenges as it pursues the goals it has set out.

\section{The Future}

It is ironic that the Refugee Resettlement Model was originally entitled the Integrated Operational Delivery Model, because in fact it is at the policy level that the RRM has had its greatest success. The guidelines for diminishing "ability to establish" criteria and refugee family reunification have been universally endorsed. Furthermore, while the UPP is still subject to evaluation, there has been little or no criticism of the policy guidelines, outside of general concerns about Canada's security restrictions.

While policy should come before operational change, on the operational side, Canada is slow to alter its refugee processing in response to new realities. This is not to say that new measures have not been taken, but that these measures may not be able to keep pace with new demands.

Canada has made significant progress in diminishing its "ability to establish" criteria, in developing policy on refugee family reunification, and establishing at least a model for urgent resettlement. However, for the vast majority of refugees, Canadian processing remains slow.

The Urgent Protection Pilot raises questions about how this project could be more universally available, since refugees with protection concerns are not limited to the three sites in which the participating visa offices are located. While during the pilot some innovation has been shown, it was difficult to have cases considered that were not in the same location as Canadian missions. In order to process urgent cases, waiving interviews should be the norm (based on the submission of the UNHCR's Refugee Resettlement Form), with interviews being conducted only if there are particular concerns surrounding a submission. The Canadian visa office in Ankara waived virtually every interview. At the other missions, visa officers still required interviews (some extremely lengthy despite the urgency of the submission). This might raise questions about the quality of UNHCR submissions. Nevertheless, for urgent processing to work, it requires substantial trust between the UNHCR and the Canadian mission, in which the mission is confident in the quality of the submissions, and the UNHCR is certain that the mission will respond to urgent requests quickly and without lengthy scrutiny.

The issues for the future for Canada will not likely be "ability to establish" criteria, since visa officers are already diminishing its application (though its continued presence is an annoyance in the face of protection concerns). Instead, medical and security restrictions are likely to be the new obsessions. Unfortunately, these problems will be far more difficult to overcome than diminishing "ability to establish" criteria.

Canada's medical requirements are a problem on two levels. Until Canada amends its Immigration Regulations, Canada continues to be able to refuse individuals on the basis of excessive medical demand. The irony is that a refugee's medical disability that Canada views as costly, may be the basis upon which the individual was viewed as needing resettlement. One hopes that if future legislation mirrors the policy commitments stated in the c-31 legislative package, this barrier will be removed for refugees and familyclass applicants.

The second issue is that medical restrictions mean that medical examinations must be conducted. However, in parts of the developing world where refugees needing resettlement are located, there is a lack of available medical facilities and weak infrastructures, making the completion of medical exams logistically difficult.

In addition, there has been a recent surge of reports in the media about newcomers and health problems (tuberculosis, malaria, HIV). While these issues are yet to be resolved, and the true impact of these health concerns are not yet evaluated, it will be important that the goal of screening out those who pose a genuine risk to Canadian health is not used as a way to bar the admission of those in need of resettlement.

Security is a growing preoccupation for Canada, demonstrated within the current act and regulations and made more severe in Bill C-31. This is increasingly problematic for resettlement. The UNHCR screens individuals on exclusion grounds, yet it is having increasing difficulty working with Canada because of its security restrictions. What has been frustrating is that while Canada has refused individuals on security grounds, the UNHCR has found other countries such as the United States and the Netherlands willing to resettle these same individuals. Furthermore, in addition to its security preoccupations, Canada can also be slow in conducting security reviews, causing frustration for visa officers as well.

In Africa, where some of these medical and security problems are greatest, there is also the danger that Canada's program will be lost in the shadow of the American program. Canada's resettlement program in Africa in 2001 is likely to be just over one-tenth the size of the American program. If other countries are perceived to have fewer barriers than Canada, particularly for urgent cases, which are often high-profile cases that may be perceived as security concerns, it is likely that in the interest of the safety of the refugee involved, the UNHCR will not approach Canada because it will likely face refusal and risk wasting valuable 
time. As a result, Canada will not be able to achieve its policy objective of urgent processing. Instead, we will be back to the days when it was true that "if the case is urgent, don't approach Canada."

Despite these new challenges, Canada continues to process refugees for resettlement in the same manner it has for the past two decades. While it is impossible to predict the refugee emergencies of the future, it is quite predictable that the trend for refugee selection over the next few years will be continued growth in Africa, the Middle East, and South Asia-the very places that Canada faces its greatest operational challenges. Canada's resettlement program must continue to evolve if it is going to be responsive to these resettlement needs and meet the policy objectives it has set for itself.

Canada might consider several initiatives in order to respond to these challenges:

1. Implement the C-31 Legislative Package resettlement proposals As part of any new legislation, Canada should reintroduce the proposed C-31 measures of removing or diminishing the regulatory requirements to consider a refugee's "ability to establish" as an admissibility factor, and removing the excessive medical cost barrier for refugees.

2. Devise a resettlement system based on priorities In keeping with its resettlement initiatives and the efforts it has made to improve selection processing, Canada needs to develop a system of resettlement priorities that are in keeping with those of the UNHCR. The UPP has provided some groundwork and has demonstrated what can be done.

3. Increase coordination "Contact groups" - regular gatherings of all the active resettlement countries in the field with relevant partners-have been promoted as an approach, but they been slow to get off the ground in some areas. Improved coordination is one of the few ways Canada and other resettlement countries may help to overcome the logistical difficulties they face. In this vein, increased efficiencies should be pursued. Canada already does so through the development of Overseas Service Partners, which ideally will increase efficiency.

4. Share processing Given the difficulties of accessing refugee populations, shared processing among the three largest resettlement countries (Australia, Canada, and the United States) needs to be strengthened. This approach can prevent problems of dual processing - two countries attempting to process the same case-as well as ensuring that priority cases are dealt with first. Similarly, the development of common resettlement criteria based on UNHCR criteria is needed so that the UNHCR can find a solution for those needing resettlement.
5. Introduce common medical examinations In the same vein as shared processing, one obvious area where countries could begin to ensure greater efficiency is the development of common medical criteria and the use of the same designated medical practitioners and panel physicians. It is obviously inefficient when a case is refused by one country, then is forced to complete a new medical exam for another country, especially when it is difficult to organize medical exams. Some movement may begin on this area in East Africa.

6. Waive interviews for urgent cases During the UPP an increasing source of frustration has been the difficulty of responding to cases that were outside of the location in which a Canadian visa officer was present. Waiving interviews, based on the content of the UNHCR's Refugee Resettlement Form when urgency is involved, should be the norm and must be pursued. A program intended to respond to urgent submissions must be built on a strong relationship of trust and quality submissions. This model has worked well in Turkey, where the UNHCR and the Canadian embassy developed a strong relationship of trust and confidence, which has allowed interviews to be waived in urgent cases based on the information contained in the UNHCR's Refugee Resettlement Form (RRF). In the same vein, when urgent submissions are made, the content of the submission cannot be subject to scrupulous examination if the urgency of the case is to be respected.

7. Introduce screening of RRF submissions by UNHCR regional resettlement officers before they are submitted to resettlement countries for consideration If countries are to waive interviews of UNHCR cases when appropriate, they must be confident in the quality of UNHCR submissions. In turn, the UNHCR must ensure that staff selecting refugees for resettlement are knowledgeable about its own criteria and those of resettlement countries. Regional Resettlement Officers need to review and screen resettlement submissions before they are submitted to resettlement countries, so that accuracy and high quality are ensured.

8. Develop a Headquarters Referral System Given the few places where Canadian visa officers are stationed, new systems must be developed in order to respond to urgent cases that are far removed from visa offices. The solution should include a "headquarters referral system." This would mean that in areas where Canada has no active or accessible Canadian mission with a resettlement program, UNHCR headquarters should be able to directly submit urgent protection cases to CIC headquarters in Ottawa. For this system to work, cic headquarters would need to have the ability to admit such individuals if they meet Canadian criteria. 
While such an approach would be extraordinary for Canada, restricting headquarter submission to urgent protection cases submitted by UNHCR headquarters, would ensure that the cases submitted are genuinely urgent.

None of these ideas are particularly innovative. However, it may take a great deal of innovation for Canada to ensure that its resettlement program will be a tool of protection and a durable solution, and be responsive to refugees in need of resettlement, today and tomorrow.

\section{Notes}

1. Canadian Council for Refugees, "Background: 7,300 Government-Assisted Refugees to Arrive in 1998-What's in a Number?" (Montreal: cIC, February 1998).

2. UNHCR, Resettlement Handbook (Geneva: UNHCR, 1998 rev.), chapter 4 .

3. UNHCR, Resettlement Handbook (Geneva: UNHCR, 1998 rev.), IV/2.

4. Citizenship and Immigration Canada, Building a Strong Foundation for the $21^{\text {st }}$ Century: New Directions for Immigration and Refugee Policy and Legislation (Ottawa: CIC, 1999), 43.

5. The countries that have an annual refugee resettlement "quota" are Australia, Canada, Denmark, Finland, The Netherlands, New Zealand, Norway, Sweden, Switzerland, and the U.S.A.

6. UNHCR, Report on UNHCR Resettlement Activities (Geneva: UNHCR, June 2000), 4.

7. UNHCR, Evolution of Resettlement Policy and Refocusing of Operations Worldwide (Background note for the agenda item Reflection on the Changing Nature of Resettlement and the Impact upon the Operational Environment) for the Annual Tripartite Consultation on Resettlement (Geneva: UNHCR, 3 July 2000), 4.

8. Associated Press, "U.S. Policy toward African Refugees Flawed, Critics Charge," November 13, 2000.

9. UNHCR, Report on UNHCR Resettlement Activities, 6.

10. Citizenship and Immigration Canada, "Refugee Resettlement Eligibility and Selection Criteria: Implementation of Policy," discussion paper (Ottawa: CIC, 2000), 3-4.

11. Canadian Council for Refugees, "Refugees Worldwide, Assessment of Global Resettlement Needs and Resettlement in Canada, Statistical Overview 1993-1996" (Montreal: cCR, February 1997).

12. CIC, Urgent Protection Pilot, OM 4655-5-10/UPP, December 1999.

Michael Casasola is director of the Refugee Office of the Roman Catholic Diocese of London. He has been involved in the development of the RRM, especially when a member of CIC'S RRM Overseas Team, and has worked with the UNHCR as a resettlement officer in Canada.

(C) Michael Casasola, 2001. This open-access work is licensed under a Creative Commons Attribution-NonCommercial 4.0 International License, which permits use, reproduction and distribution in any medium for non-commercial purposes, provided the original author(s) are credited and the original publication in Refuge: Canada's Journal on Refugees is cited. 